\title{
What happens when children speak a different language from that of the teacher in a learning setup?
}

\begin{abstract}
Language Policy in education demands that preschool children be taught in their mother tongue. This is challenging, particularly when the language of the teacher and that of the preschool children are different. Previous research studies both global and local have majorly concentrated on the importance of using mother tongue as the language of instruction in preschool, but do not identify the challenges faced by pre-school teachers in instructing children from diverse linguistic backgrounds. The objective of this study was to establish the linguistic diversity among pre-school children entering preschool. The study is anchored on Linguistic relativity theory by Sapir and Whorf (1884-1939) which states that the way people think is strongly influenced by their native languages. This study used a descriptive research design. The study was conducted in Nyakach Sub- County in Kisumu County. The study found that preschool children enrolled into the schools within Nyakach sub-county are linguistically diverse. The challenges faced by teachers of children who do not speak and comprehend the language used by the teachers are; language barrier, limited learning and inactive children in class activities. It is recommended that linguistic diversity be considered when employing pre-school teachers, while in areas and schools with diverse linguistic composition, teachers be equipped with skills to handle diverse learners.
\end{abstract}

Keywords: Linguistic diversity, pre-school children, diverse linguistic composition, teachers, language challenges, class activities, code-switching, languages, curriculum content, language barrier, limited learning, inactive children
Special Issue - 2018

\author{
Judith Atieno Opinde,' Catherine Gakii \\ Murungi ${ }^{2}$ \\ 'Chair ECD, Adult Education and Training, Kisumu County \\ Assembly \\ ${ }^{2}$ Department of Early Childhood Studies, Kenyatta University
}

Correspondence: Catherine Gakii Murungi, Department of Early Childhood Studies, Kenyatta University, PO-43844-00 I00, Nairobi, Kenya, Email Catharine_gakii@yahoo.com

Received: July 12, 2018 | Published: December 31, 2018

\section{Research objectives}

To find out language related barriers experienced by the preschool children who do not speak or comprehend the language of catchment area.

\section{a. Research questions}

Is there linguistic diversity among children entering preschools?

\section{b. Linguistic diversity among children entering preschool}

Linguistic diversity in many parts of the world has been brought about by migration of people to different parts of the country. Consequently, most people have been confronted by linguistic diversity as the world becomes a global village Ngasike. ${ }^{1}$ Schools are the most important points of contact where speakers of all languages exist Daniel \& Friedman. $^{2}$ This therefore calls for a language that can be used to instruct learners at the same time enhancing healthy teacher- child interactions. A child's success in school can be as a result of several events including language related issues. The quality of a child's language experiences in their preschool years is very important. ${ }^{3}$ Opines that through language children learn about their world and communicate their views. Language is very essential in learning as it is necessary for interaction in the learning environment as well as comprehension of curriculum content. Unfortunately some children experience language challenges when they enter preschools. Some of these challenges have been occasioned by linguistic diversity of children entering preschools.

Kenya is ethnically heterogeneous with a population of over 40 million people speaking over 50 languages. ${ }^{4}$ The language policy recognized the challenges faced as a result of diversity and attempted to implement mother tongue in areas where one ethnic group resides. In areas with different groups Kiswahili or English was to be used. ${ }^{1}$ This policy however, does not mitigate on the challenges faced by children who due factors like migration to places where their languages are not used face. There are children who come to school and find that the language used in school is different from the one they are familiar with. This makes these children to use code-switching to other languages in order to communicate. ${ }^{5}$ Study done by Mbaabu, ${ }^{6}$ shows that admission of children to preschools is not pegged on the language of instruction hence all preschools admit children from diverse linguistic backgrounds. Further the language of instruction is not considered when recruiting preschool teachers. This means that there are preschool teachers teaching children with the language the children are not familiar with. Since learners linguistic background is not considered when admitting children to the preschools, it is common to find teachers who are unfamiliar with the child's language in E.C.D. classrooms. ${ }^{7}$ This therefore means that there is curriculum content that are taught and not understood by the children. Efforts should therefore be made to ensure children are helped to understand what they are taught.

\section{c. Research Design}

This study adopted a descriptive research design using survey method. The descriptive design was preferred because it allows the participants to describe the difficulties they face in an accurate way. The qualitative approach which entails the use of questionnaires to gain a deeper understanding on language related barriers in teacherchild interaction in preschool was used. The survey method allows 
participants to answer questions on issues affecting them hence was useful in the study. The qualitative approach was used because it is flexible hence allows the researcher to get in-depth information through the use of open-ended questions in the questionnaires.

\section{Research method}

The study adopted qualitative approach where the questionnaires were used to collect data.

\section{a) Location of the study}

The study was conducted in Nyakach sub County in Kisumu County. Nyakach Sub County has three divisions, which are Lower Nyakach, Upper Nyakach and West Nyakach. The sub county is cosmopolitan in nature having several communities settling together for economic reasons. The area is predominantly occupied by the Luo community. The language of the catchment area is Dholuo. However there are other communities living among them with young children who are enrolled in the preschools within the sub- County. This therefore means that learning should be conducted in Kiswahili according to the language in education policy. This brings in the challenge to both teachers and children as the language (Kiswahili) is rarely used outside the school environment. The location therefore has challenges related to language of instruction. The required data was sought from the preschools in the sub-county. This location was selected owing to its cosmopolitan nature, since it harbours Sondu town, Nyabondo Complex, Pap Onditi sub-county headquarters inhabited by people from various communities working and doing business in the region hence the schools have children and teachers who experience language related barriers in their classrooms (Table $1)$.

Table 1 Distribution of target population

\begin{tabular}{lll}
\hline Category of school & Percentage & Number of teachers \\
\hline Public & 70 & 72 \\
Private & 30 & 13 \\
\hline
\end{tabular}

Source: Research Data

\section{b) Sampling techniques and sample size}

Sampling technique is the process of identifying the entities to be included in a sample. Sample size on the other hand is the number of observations in a sample. ${ }^{8}$

\section{c) Sampling technique}

A sample is a small portion of the target population. Mugenda \& Mugenda ${ }^{9}$ suggest that a sample between $10 \%$ and $30 \%$ of the accessible population is adequate to serve as a study sample. There are three divisions in Nyakach Sub County these are upper, lower and west Nyakach with eight zones. The study adopted purposive and simple random sampling technique to obtain the study sample. Out of the three divisions purposive sampling technique was used to select upper Nyakach division for the study. This is because it is more cosmopolitan. In the division there are eight zones. The researcher used simple random sampling using lottery method to select three zones for the study Tromp \& Kombo. ${ }^{10}$ The three zones selected provided the schools where the teachers included in the study was obtained. Since there are both public and private preschools, each category was represented. $70 \%$ of the public preschool teachers were included while private preschool teachers constituted $30 \%$ of the study sample. Preschool teachers were purposively selected to get the ones to be included in the study. This was necessary owing to the classroom composition of the children in certain classes and the linguistic diversity of the teachers because these teachers are in a position to inform the study on their experiences due to linguistic diversity.

\section{d) Sample size}

This study used a sample size of 85 preschool teachers from both public and private preschools, this represented $70 \%$ and $30 \%$ respectively. All these came from upper Nyakach owing to its cosmopolitan nature (Table 2).

Table 2 Distribution of sample size

\begin{tabular}{lllll}
\hline Division & Zones & $\begin{array}{l}\text { Category of } \\
\text { Schools }\end{array}$ & $\begin{array}{l}\text { Number } \\
\text { of } \\
\text { Teachers }\end{array}$ & $\begin{array}{l}\text { Total } \\
\text { Number of } \\
\text { Teachers }\end{array}$ \\
\hline Upper Nyakach & 1 & Public & $50 \%$ & 72 \\
& 2 & Private & $30 \%$ & 13 \\
\hline
\end{tabular}

Source: Research Data

\section{e) Data analysis}

Data analysis was done qualitatively. Data was first sorted and coded. The codes were assigned to each item in the questionnaire and a code list obtained. Data was then grouped into categories to get related items. After categorization data was interpreted, presented and discussed according to the objectives of the study and conclusions drawn from the issues addressed by the respondents.

\section{f) Demographic information}

This section gives the data in raw form, indicating how the respondents understood the questions. Data presentations cover biographical data of the respondents. The data is presented in Table 3.

\begin{tabular}{lllll}
\multicolumn{2}{l}{ Table 3 Biographical data } & & \\
\hline \multicolumn{1}{l}{ Biographical data } & & & & \\
\hline Category of school & Public & Private & Total & \\
& 54 & 24 & 78 & Others \\
Highest qualification & Certificate & Diploma & Degree & 6 \\
& 41 & 23 & 8 & Total \\
Teaching experience & $0-5$ years & $5-10$ yrs & over 10 years & 78 \\
& 43 & 32 & 3 & \\
\hline
\end{tabular}

\section{Source: Research Data}

\section{g) General information}

The data collected showed that the majority of the respondents at $69.2 \%$ were from public schools, while $30.8 \%$ were from private schools. Teachers handling the preschool children were trained from certificate to degree level. Data showed that $52.6 \%$ of the teachers were trained to certificate level, $29.4 \%$ diploma level and $10.3 \%$ degree level. Only $7.7 \%$ of the preschool teachers who responded to the questionnaires were untrained form four leavers employed by the school boards in the village schools. The teaching experience of the respondents showed that the majority $(55 \%)$ of the teachers had worked as preschool teachers for less than 5 years as a result of the recruitment by the county government of Kisumu. Very few teachers had worked for more than 10 years as pre-school teachers. 
Table 4, presents the data on linguistic diversity of children enrolled in pre-school in Nyakach Sub County, Kisumu County. The data indicate that 63 out of 78 teachers agreed that they had children from diversified linguistic backgrounds in their classes. Similarly, when asked the same question differently, nearly equal number of 62 out of 78 agreed that they have children in their classes who do not understand the language used in teaching. The data presented in Table 4 , above directly responds to objective one of the studies that assesses the linguistic diversity of children enrolled in the pre-schools within Nyakach sub-county. This indicates that it is a reality that there are children who are enrolled in preschools without the ability to use the language used by the teachers to instruct them. This therefore makes teacher- child interactions to be difficult as the teacher and the child are not able to have effective communication. When communication is not effective, learning is also minimal since language is fundamental to learning (Table 4).

Table 4 Linguistic diversity

\begin{tabular}{lllll}
\hline Language Diversity in Schools & Yes & No & Total \\
\hline & 63 & 15 & 78 \\
$\begin{array}{l}\text { Language diversity of children admitted in your } \\
\text { class }\end{array}$ & & & \\
$\begin{array}{l}\text { Do you have Children who do not understand } \\
\text { the language you use to teach them? }\end{array}$ & 62 & 16 & 78
\end{tabular}

Source: Research Data

Language is required for interaction in the learning environment and comprehension of curriculum content. The main language related barriers faced by the respondents are presented in figures. There are children enrolled in the pre-school handed over to teachers who are unable to teach in the language they understand. When asked that question, 62 pre-school teachers agreed that the enrolment is done based on age but not the language. There are teacher-child interactions difficulties faced by teachers according to Table 5 which includes language barrier, limited learning and children being inactive in the class activities and are usually silent. The table also present the responses on the alternative languages the teachers often use when unable to teach using the language of catchment area. Detailed analysis of the findings is in section 4.3 .

Table 5 Language related barriers faced by teachers

\section{Language related barriers faced by teachers}

\begin{tabular}{lll}
\hline $\begin{array}{l}\text { Do you have children who do not understand } \\
\text { the language you use to teach them }\end{array}$ & Yes & No \\
$\begin{array}{lll}\text { Challenges faced by teacher who do not speak } \\
\text { language of local community }\end{array}$ & $\begin{array}{l}\text { Language } \\
\text { barrier }\end{array}$ & $\begin{array}{l}\text { Limited } \\
\text { learning }\end{array}$ \\
62 & 16 \\
How do the children cope with class activities & $\begin{array}{l}\text { They are } \\
\text { silent }\end{array}$ & Active \\
& 50 & 28 \\
Which alternative language is used other than & Kiswahili & English \\
The local language & 56 & 22 \\
\hline
\end{tabular}

Source: research data

\section{Findings}

\section{Language related barriers experienced by pre-school children}

Analysis of the data shows that the pre-school teachers are aware of the language policy that requires pre-school children to be instructed using the language of the catchment area. The data indicated that only 6 out of $78(7.7 \%)$ respondents who were particularly the untrained teachers were not aware of the policy by Ministry of education (MoE) that pre-school children be taught using mother tongue or the language of the catchment area. Despite the awareness by the majority of the teachers concerning the language policy, only $15.4 \%$ noted that there are lessons taught in mother tongue of the children, while the majority $(84.6 \%)$ declined that there are no lessons taught in mother tongue in their classes. This finding is a confirmation that teachers use a language of instruction that is not fully understood by the children. Menken and Garcia ${ }^{11}$ also found out that not all policies on language of instruction are implemented as stipulated. The teachers in the schools studied showed that none of them upholds the policy of instructing children using mother tongue due to school factors. The children therefore face the challenge of inability to understand and follow the class instructions. When a child experiences difficulties in communicating, the child might fall behind in school activities and struggle with situations that rely on language like play.

When asked the challenges they face when teaching in Dholuo, a third of the pre-school teachers said that they experience no challenge since all the children they instructed were all from the Luo ethnic group. More than half of the teachers said that some the children they teach do not understand Dholuo and as a result do not actively participate in the class activities unless the teacher repeats the instruction in Kiswahili. The challenge based on the language barrier is that learning is either slow or no learning at all. Further analysis found that $(17.9 \%)$ of the pre-school teachers could not fully understand or speak the language of the catchment area (Dholuo). This forces them to use either English or Kiswahili languages to teach. As a result, they are unable to instruct the children using mother tongue. The use of Kiswahili and English languages present significant language barrier to the children since it is not used outside the learning environment. ${ }^{12-14}$

Similar findings are arrived at when English is used as the instruction language, since most of the children could not fully understand and speak in English. Most children remain quiet and nonresponsive when asked a question that needs response or do not participate in class activities. For instance, $(39.7 \%)$ of the preschool children partially understand and speaks English, (14.1\%) fully understands and fluently speaks English, while $46.2 \%$ do not understand English completely during enrolment. This means that when English is used as the language of instruction, majority $85.9 \%$ of children, which is a combination of those who do not understand English completely and those that partially understand English will experience language barrier leading to slow or no learning at all. The findings are presented in below Figure 1.

The analysis also showed that less than half of pre-school teachers used real objects to handle the challenges faced by the children, particularly those who do not understand the language of instruction. The real objects allow the children to see and connect to what the teacher says, thus facilitating communication between the teacher and the child. The remaining $51.3 \%$ of the respondents said that they 
use Kiswahili language to communicate with the children who do not understand either the language of the catchment area or English. The analysis responds to research objective three that sought to determine the language related barriers experienced by pre-school children who do not understand the language of the catchment area.

These findings show that most children are taught using unfamiliar language. This because $15 \%$ of the children fully understand the language used by the teachers. This in essence means that most of the children do not understand what the teacher is saying and thus feel frightened by the school situation. This may lead to school drop outs. UNESCO, revealed that $50 \%$ of children are out of school because of language used in schools. ${ }^{10}$

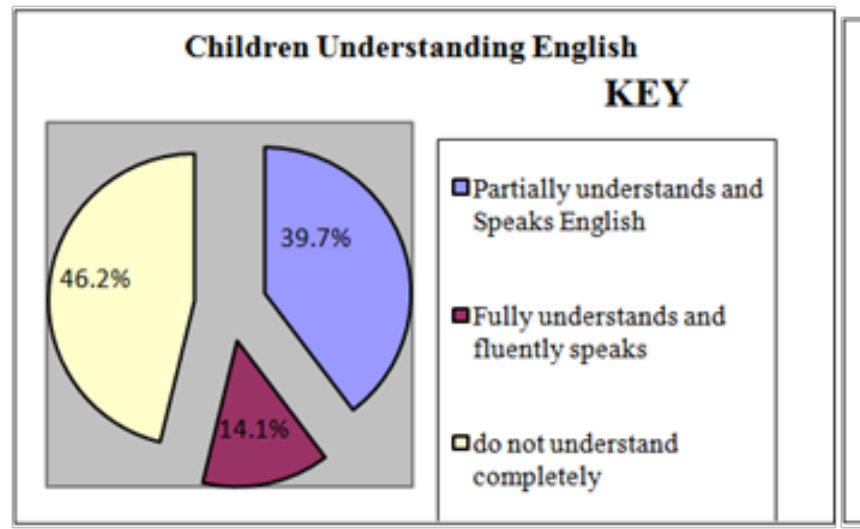

Figure 1 Language related barriers experienced by pre-school children

\section{Recommendations}

\section{Recommendation for policy}

In areas with single language of catchment area as in the rural areas, the study recommends that language of instruction be considered when employing pre-school teachers to ensure that teachers are able to communicate with the learners for better understanding.

\section{Conclusion}

The study sought to investigate the language related barriers and teacher-child interactions in preschool in Nyakach sub county, Kisumu County. Based on the findings, the study concludes that language barrier impedes interaction between the teachers and the pre-school children, leading to limited learning. Language barrier resulting from the teachers' preference of using English and Kiswahili as opposed to the mother tongue. The study found that language barrier limits interaction between the teachers and the pre-school children in Nyakach Sub County, and this makes the children silent and passive in class activities, thus slowing the learning process and quality.

\section{Acknowledgments}

None.

\section{Conflicts of interests}

Author declares that there is no conflict of interests.

\section{References}

1. Ngaske J T. Turkana children's rights to education and indigenous knowledge in science teaching in Kenya. New Zealand Journal of Teachers' Work. 2011;8(1):55-67.

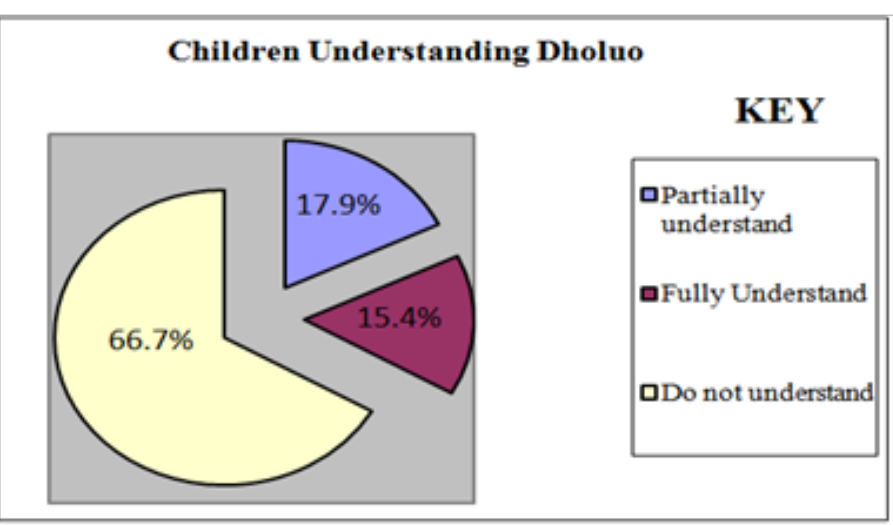

2. Daniel J, Friedman S. Preparing teachers to work with culturally and linguistically diverse children. Embracing Diversity. 2005;1-7.

3. Fasold, R. Variation Theory and Language Learning: In Applied Sociolinguistics. Peter Trudgill, ed.London: Academic Press, 1984. 1986;8(2):213-214.

4. Githiora. Swahili and Gikuyu Languages and Linguistics. 2008.

5. Muthwii M. Language Policy and Practices in Education in Kenya and Uganda. Nairobi: Phoenix Publishers. 2002.

6. Mbaabu I. Language policy in East Africa. Nairobi: Educational Research \& Publication.1996.

7. Githinji W. A situational analysis of language of instruction in lower primary schools in Nyeri County, Kenya. 2014.

8. Evans M, Hastings N, Peacock B. Statistical Distribution. 3rd ed. New York: Willey

9. Mugenda OM, Mugenda AG. Research methods: quantitative and qualitative approaches. African centres of technology studies. Nairobi. 1999, 2003.

10. Tromp LA, Kombo DK. Proposal and Thesis writing: An Introduction. Paulines Publications, Africa UNESCO (2008). International year of Languages. 2006.

11. Menken K, Garcia O. Challenges for Language education and policy. 2010 .

12. Ackers J, Hardman F. Classroom interaction in Kenya Primary schools. 2001.

13. Grace WB. Teacher preparation and continuing professional development in Kenya. Learning to teach early reading and Mathematics. 2013.

14. Halliday MAK. Aims and Perspectives in Linguistics. Applied Linguistics Association. 1977. 